\title{
PERSPECTIVE
}

\section{Managing soil quality for humanity and the planet}

\author{
Rattan LAL (凶) \\ Carbon Management and Sequestration Center, The Ohio State University, Columbus, OH 43210, USA
}

Abstract Rather than a human-centric, the basic strategy of achieving Sustainable Development Goals must be focused on restoring and sustaining planetary processes. The urgency of meeting the demands of the humanity must be reconciled with the necessity of enhancing the environment. Increasing and restoring soil organic matter content of the degraded and depleted soils is critical to strengthening planetary processes.

Keywords soil quality, humanity, planet, climate change, soil carbon sequestration, food and nutritional security

\section{Introduction}

Humanity is faced with the daunting challenge posed by the tragedy of the COVID-19 pandemic that emerged towards the end of 2019. The problem is aggravated by the large and ever-growing human population, with numerous demands for finite and fragile planetary resources. Yet, achieving human demands by jeopardizing planetary resources and the associated processes is not appropriate to sustainable development. The shortsighted and myopic approach must be revisited to ensure that the goals are meeting the demands of humanity while operating in harmony with nature and within the planetary boundaries.

Critical systems for the optimal functioning of planetary processes include the atmosphere, hydrosphere, biosphere and pedosphere (Fig. 1(a)). The primary determinant of pedosphere processes is soil organic matter (SOM) content, stock and dynamics. The SOM moderates biogeochemical and biogeophysical cycles, water purification and renewability, and activity and species diversity of soil biota (Fig.1(b)). The SOM (quantity, quality, turnover) affects planetary processes through moderation of soil quality and functionality comprising of physical, chemical, biological, and ecological properties and processes (Fig. 1). Restoration and sustainable management of soil quality and functionality also impacts Sustainable Development Goals (SDGs) ${ }^{[1]}$.

The tragedy of the pandemic caused by COVID-19 necessitates revisiting the idea of sustainable development ${ }^{[2]}$. The demands of the ever-growing and increasingly affluent humanity must be reconciled with the absolute necessity of restoring and strengthening the planetary processes. Strengthening of planetary processes, through a judicious management of the Anthropocene, must be the basis of sustainable development. The human-centered focus of the SDGs, with disregard to planetary processes, may be counterproductive.

\section{Sustainable development and planetary processes}

The widespread perturbations leading to irreversible changes of natural processes, often under the disguise of sustainable development, must be reconsidered, both critically and objectively. Some examples of such irreversible perturbations include tropical deforestation, drainage of peatlands, removal of topsoil for brick making, strip mining of fossil fuels and other minerals, and indiscriminate and unplanned urbanization. Banning further agricultural expansion and limiting the use of nitrogen, phosphorus and pesticides are critical to

Received April 23, 2020

Correspondence: 1al.1@osu.edu

(c) The Author(s) 2020. Published by Higher Education Press. This is an open access article under the CC BY license (http://creativecommons.org/licenses/by/4.0) 


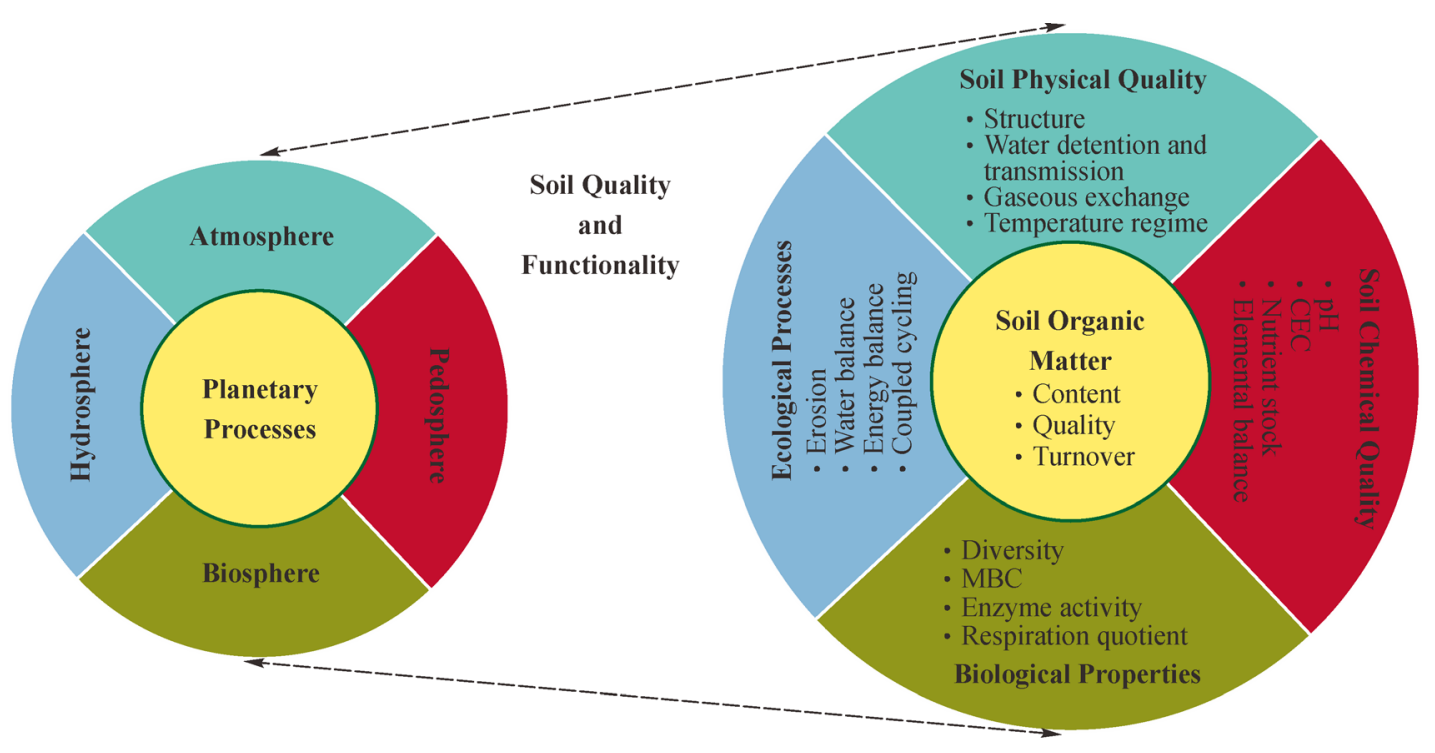

(a)

(b)

Fig. 1 (a) Soil quality moderates planetary processes. (b) Soil organic matter (content, quality, turnover) moderate soil physical, chemical, biological and ecological quality.

curtailing degradation and strengthening the planetary processes.

Therefore, SDGs must be achieved through adoption of a systems approach ${ }^{[3]}$ that maximizes synergisms. A strategy involving synergisms, based on the One Health initiative, is outlined in Fig. 2. Human and planetary health must be achieved through management of soil health through a judicious and prudent governance.

\section{The way ahead}

The human-centric approach, taming and conquering nature by crossing planetary boundaries, is counter to human wellbeing and functioning of nature. It is in humanity's best interest to live in harmony with nature.

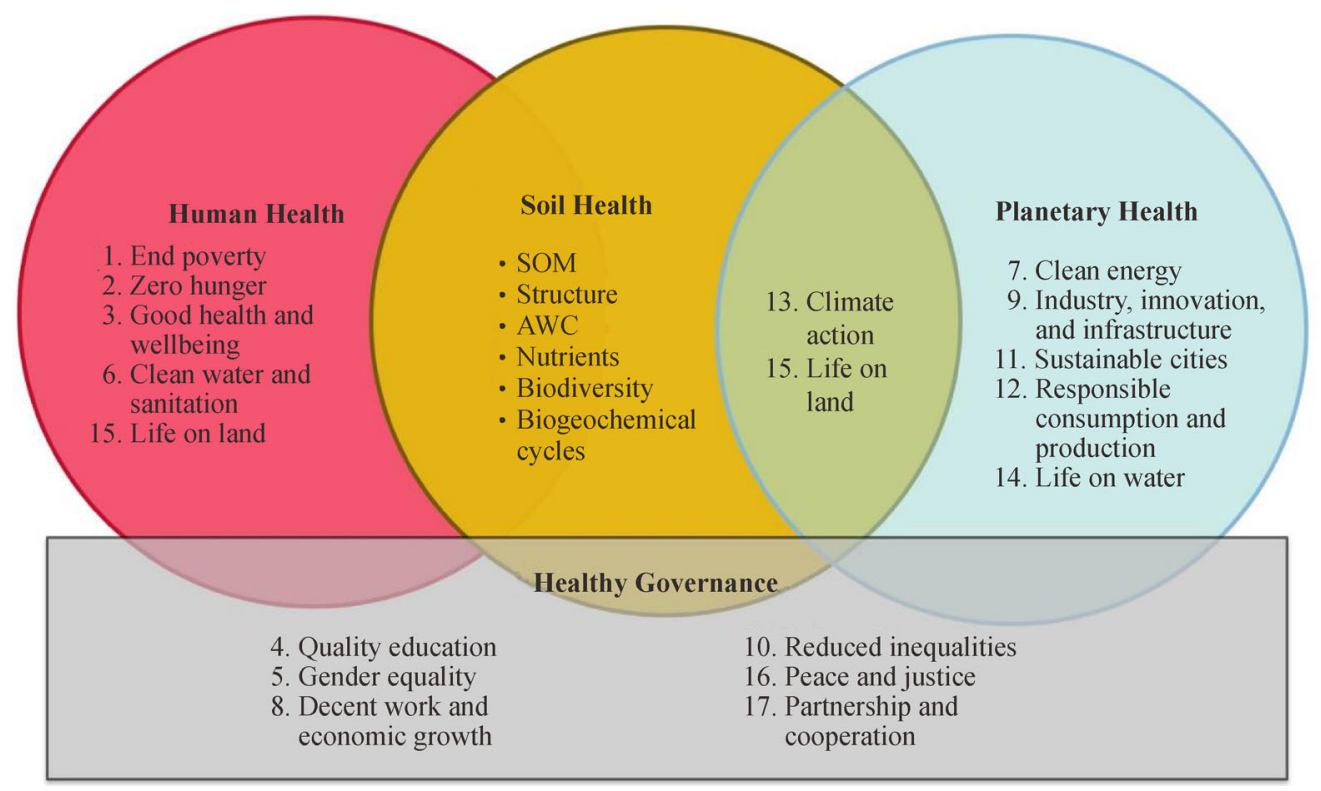

Fig. 2 Synergistic approach to advance Sustainable Development Goals (SDGs) ${ }^{[1]}$ through sustainable management of soil health for human health and planetary health through healthy governance. 1-15, SDGs; AWC, available water capacity; and SOM, soil organic matter. 
Quality education (SDG4) must focus on the concept of "planet first". In accord with One Health, it is important that soil quality act be adopted at the local, national and global levels. The environmental trinity - soil, water and air - involve specific legislation to strengthen the planetary and human health (Fig. 3). Restoration and sustainable management of soil quality, through sequestration of SOC stock in agroecosystems, is critical to advancing SDGs.

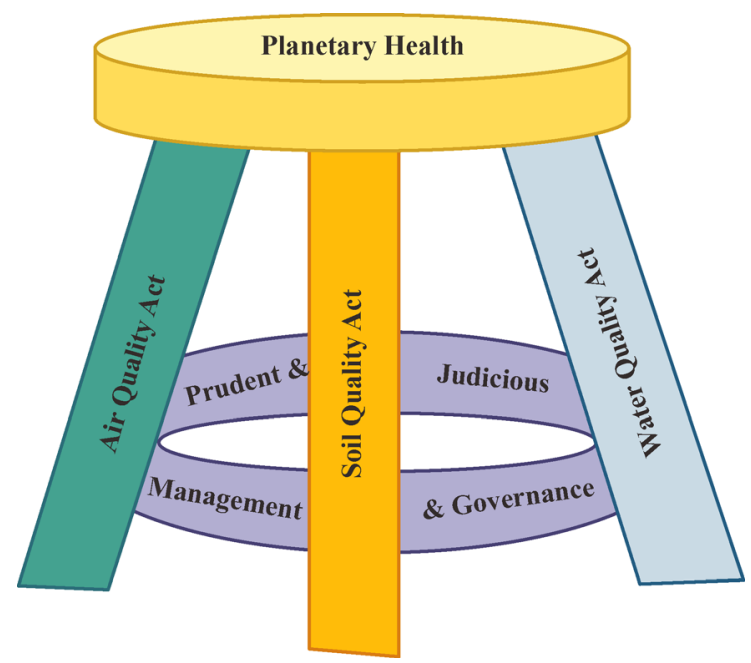

Fig. 3 Legislation is needed at the local, national and global levels to strengthen planetary health through formulation and implementation of trinity acts: soil quality act, air quality act and water quality act.

\section{Conclusions}

Restoration and sustainable management of soil quality, through buildup of SOM, is an essential prerequisite to achieving several SDGs (2, zero hunger; 13, climate action; and 15, life on land). Rather than human-centered, SDGs must be focused on restoration of the planetary processes. Legislation is needed to strengthen the environmental trinity based on a soil quality act, Water Quality Act (1965) and Air Quality Act (1967). Protection and restoration of soil, water and air is essential to advancing SDGs.

\section{References}

1. Griggs D, Stafford-Smith M, Gaffney O, Rockström J, Öhman M C, Shyamsundar P, Steffen W, Glaser G, Kanie N, Noble I. Policy: sustainable development goals for people and planet. Nature, 2013, 495(7441): 305-307

2. Pirouz B, Shaffiee Haghshenas S, Shaffiee Haghshenas S, Piro P. Investigating a serious challenge in the sustainable development process: analysis of confirmed cases of COVID-19 (new type of coronavirus) through a binary classification using artificial intelligence and regression analysis. Sustainability, 2020, 12(6): 2467

3. Zhang Q, Prouty C, Zimmerman J B, Mihelcic J R. More than target 6.3: a systems approach to rethinking sustainable development goals in a resource-scarce world. Engineering, 2016, 2(4): 481-489 